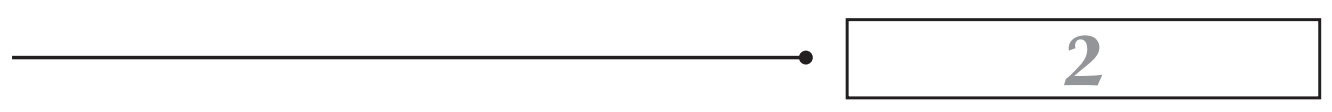

\title{
FINALIDADES DA EXECUÇÃO ORÇAMENTÁRIA
}

A execução do orçamento é o "conjunto de atividades destinadas ao cumprimento dos programas estabelecidos para alcançar os objetivos propostos" ${ }^{154}$ Quanto mais estreita a associação entre planejamento e orçamento, destacando-se a técnica do orçamento-programa, maior tende a ser o envolvimento de todos órgãos da administração, a partir do estabelecimento das unidades orçamentárias que serão responsáveis tanto pela programação como por sua execução.

Em um sistema de execução orçamentária que se fundamente na atribuição de competências a diferentes agentes, normal e predominantemente situados no âmbito do Poder Executivo por seu caráter administrativo, essa divisão deve ser a mais clara possível, de modo a evitar superposição e a consequente redução da eficiência da organização administrativa. Com isso, ganhou bastante importância, nos mais diversos sistemas orçamentários, uma tradicional divisão de funçôes e responsabilidades entre a unidade programadora e a unidade executora do orçamento. Cabe àquela a programação e a coordenação das atividades do órgão que deve executar o programa, estabelecendo o fim de cada projeto, as prioridades e a administração dos créditos orçamentários. Compete à unidade executora a consecução dos projetos, sob a perspectiva da construção das unidades físicas que cada um deles objetiva.

Diz-se tradicional porque a distinção é bem desenvolvida em outros sistemas jurídico-orçamentários. As normas referentes à gestão das finanças públicas na França se eximem em destacar a diferença fundamental que deve haver entre o

154 SILVA, Orçamento-programa no Brasil, p. 306-307. 
ordonnateur e o comptable. Promove-se uma divisão orgânica e funcional de competências, permitida pela independência entre as autoridades e pela incompatibilidade entre as funções exercidas. O objetivo nítido é assegurar o controle da regularidade e da legalidade da execução da despesa. ${ }^{155}$

O sistema não é imune a críticas, em vista da influência que adquirem os conceitos gerenciais aplicados à administração pública. A estrita separação anteriormente apontada, fundada no apropriadamente denominado "princípio da desconfiança” (principe de la méfiance), em razão do excesso de procedimentos adotados a priori na execução da despesa, assegura o controle da regularidade formal, mas não fornece respostas suficientes à necessidade de eficiência e de desempenho da gestão pública, determinando procedimentos morosos, trabalhosos e excessivamente formalistas - o que pode ser em parte corrigido pela informatização dos serviços de administração financeira e orçamentária. ${ }^{156} \mathrm{~A}$ revisão desse sistema tem como escopo mais evidente dar maior liberdade à ação dos agentes, com máxima eficácia aos menores custos. Se eficiência, eficácia e efetividade são objetivos desejados para a administração pública, a desconfiança, porém, é de alguma forma justificada quando se trata de agentes que cuidam do dinheiro público - pelo que, se há méritos inequívocos nas propostas de administração gerencial, o problema dos desvios no uso do dinheiro público precisa ser corrigido em várias frentes de atuação, e não apenas nos procedimentos de execução. E, ainda mais, não só quanto aos procedimentos administrativos, mas também quanto aos políticos. Começar as reformas unicamente por diminuir a responsabilidade do ordenador da despesa, que deve verificar sua regularidade, sem promover outras modificações mais amplas na transparência, na eficiência dos sistemas de controle interno e externo exercidos sobre o desempenho, e sem introduzir instrumentos de efetiva responsabilidade dos agentes públicos e de participação democrática no sistema orçamentário, poderia representar uma indesejável substituição do "princípio da desconfiança" pelo "princípio da ingenuidade".

Quanto às finalidades, em termos bastante abrangentes se pode considerar que a execução da lei orçamentária tem os mesmos objetivos da execução de qualquer lei: cabe ao Poder Executivo aplicar as leis aprovadas pelo Legislativo, como anteriormente fundamentado. $\mathrm{O}$ exercício da atividade administrativa encontra limites na inovação das providências políticas e legislativas, e o orçamento, por suas diversas características, se enquadra em ambas. No Brasil, tradicionalmente não se

155 BOUVIER, M.; ESCLASSAN, M.-C.; LASSALE, J.-P. Finances Publiques. 7. ed. Paris: LGDJ, 2004, p. 371.

156 BOUVIER; ESCLASSAN; LASSALE, cit., p. 383. 
prevê a figura dos regulamentos autônomos. ${ }^{157} \mathrm{O}$ inciso IV do art. 84 da Constituição Federal dispõe que compete privativamente ao presidente da República expedir decretos e regulamentos para a "fiel execução" da lei, pelo que há razão em afirmar que o poder conferido ao Executivo na execução das leis é um poder subordinado.

$\mathrm{O}$ orçamento, no entanto, provavelmente lidará com necessidades urgentes e imprevistas no decorrer de sua vigência, que exigirão seu adequado enfrentamento. Ou, então, se deparará com circunstâncias financeiras imperiosas que exigirão a suspensão ou liberação de créditos votados e, muitas vezes, empenhados. Qualquer que seja a circunstância imperiosa, não são meras hipóteses os casos em que o Poder Executivo se verá na iminência de realizar propostas executórias em algum grau inovadoras da lei de orçamento. Em sistemas mais confortáveis com a ideia de regulamentos autônomos, tais como o francês, vale mesmo a afirmação de Trotabas e Cotteret, segundo quem o atendimento dessas necessidades poderia ocorrer até sem autorização legislativa para o pronto atendimento de necessidades públicas. ${ }^{158}$ Não é, porém, o caso brasileiro.

Nesse, a afirmação de que a lei de orçamento é uma autorização de gasto para o Poder Executivo poderia produzir o entendimento, aqui anteriormente contestado, de que não cabe ao Poder Legislativo atuar na fase de execução, que envolveria a produção de atos materialmente administrativos. Não se podem ignorar alguns dos escrúpulos existentes quanto à maior participação do Legislativo na execução, que fazem entender e repetir, como uma vulgata do direito orçamentário, que o Executivo é o Poder mais responsável e o interesse público deve ser protegido da ação desarticulada, para dizer o mínimo, do parlamento. Contudo, essa interpretação burocrática não se coaduna com a perspectiva constitucional.

Inegavelmente, o problema central que subjaz às atribuiçôes do Poder Executivo é a dificuldade de conciliar as prerrogativas de controle parlamentar com maior flexibilidade da gestão orçamentária. Se, de um lado, o orçamento tem uma função jurídica, que enfatiza a conformidade de todas as despesas com as normas e critérios postos, tem também uma função político-econômica, que é a de servir como instrumento de governo. A despeito da aparência de obviedade desses aspectos, eles não são conciliáveis em todas as suas dimensões.

A função jurídica do orçamento, que em seu extremo representaria uma estrita obrigação de gastar, pode até produzir um indefectível sistema de controle de

157 Com exceção do art. 84, VI da Constituição que prevê a expedição de decretos para organização e funcionamento da administração federal, quando não implicar aumento de despesa nem criação ou extinção de órgãos públicos.

158 Cf. TROTABAS, L.; COTTERET, J. Droit budgétaire et comptabilité publique. 5. ed. Paris: Dalloz, 1995, p. 102. 
regularidade dos gastos governamentais, perfeitamente condizente com a previsão inicial que foi aprovada pelo Poder Legislativo. Isso, porém, em detrimento da eficiência da realização de um programa econômico-administrativo, que deve ser em alguma medida adaptável à conjuntura e aberto a revisões ocasionais. Tais necessidades de alteração, sendo a expressão de um meio de atender ao interesse público em cumprimento de determinada política, necessitam encontrar o procedimento adequado para sua concretização. As dificuldades de uma perspectiva tão estrita da execução orçamentária trouxeram, por exemplo, uma série de dificuldades ao sistema orçamentário italiano, até a década de 1990, e ao polonês, nos quais o poder do Ministério da Fazenda se restringia a considerações formais sobre o procedimento, sem a necessária consideração sobre os aspectos do ambiente em que se insere o orçamento ${ }^{159}$ e sua necessária flexibilidade.

Em outras ocasióes, esse tipo de normatividade rígida, que forçaria ao cumprimento a um controle totalizante e inalterável das despesas, pode ter por resultado a limitação da capacidade de resposta eficiente do governo a situações imprevistas. Além disso, se essa rigidez é tantas vezes normatizada com a finalidade de conferir credibilidade a determinado país, pode-se chegar à situação contrária de perda de credibilidade se os parâmetros são tão intransigentes. ${ }^{160}$

De outro lado, é claro que um sistema de execução do orçamento demasiadamente flexível enfraquece qualquer controle que as normas atinentes exerçam sobre a conduta do agente encarregado de conduzir a concretização dos gastos públicos.

O importante trabalho de Jesse Burkhead sobre o orçamento público expõe claramente o desafio de conciliação entre as duas noções citadas. A execução do orçamento deve preservar a intenção do legislador e, ao mesmo tempo, manter a flexibilidade. A definição ideal parece simples, mas difícil de atingir. ${ }^{161}$ A grande questão da execução do orçamento é reduzir a incompatibilidade que há na manutenção da vontade parlamentar expressa na lei aprovada e mantê-la, ao mesmo tempo, maleável. Reduzir, portanto, o tradeoff existente entre a rigidez normativa da lei orçamentária e a eficiência requerida para dar respostas a situaçóes imprevistas.

Essa dificuldade de conciliação dá o tom dos objetivos que devem ser perseguidos pela execução do orçamento, que é marcada por diferentes características. Resumiu Duverger ${ }^{162}$ que,

159 VON HAGEN, J. Budgeting Institutions for Better Fiscal Performance. In: SHAH. A. (Ed.) Budgeting and Budgetary Institutions. Washington: The World Bank, 2007, p. 32.

160 VON HAGEN, cit., p. 32

161 BURKHEAD, cit., p. 342.

162 DUVERGER, M. Finances publiques. Paris: Presses Universitaires de France, 1975, p. 304, tradução livre. 
[e]m definitivo, a execução do orçamento é sempre dominada essencialmente por três espécies de considerações. Considerações políticas, em primeiro lugar: assegurar o respeito às prerrogativas do Parlamento em matéria financeira, evitando ultrapassar as autorizações orçamentárias. Considerações financeiras, em seguida: impedir esbanjamento e malversação por parte dos agentes encarregados da execução do orçamento. Considerações administrativas, enfim: assegurar uma boa gestão dos serviços públicos.

Uma conclusão que se pode obter a essa altura é que cabe falar em flexibilidade na fase de execução do orçamento apenas quando ela encontra espaço normativo de atuação. Não é possível entender, porém, que haja uma contradição entre flexibilidade e legalidade: se não à execução rigorosa dos montantes, as alterações devem se destinar à manutenção dos objetivos políticos contidos no orçamento. Tais objetivos, como foi aqui desenvolvido, subordinam decisões executórias do orçamento, e não se pode entender que haja uma irredutível oposição entre a política orçamentária do Poder Legislativo e a política orçamentária do Poder Executivo. As medidas de execução ficam adstritas à obtenção dos resultados previstos nos programas orçamentários, quer para isso seja necessário gastar todo o dinheiro previsto para ele ou não. A flexibilidade não opera em um vácuo de princípios orçamentários, e tampouco os interesses do Poder Executivo em realizar determinada política fiscal podem ignorar os objetivos orçamentários previamente traçados. $\mathrm{O}$ sistema mostra-se de alguma forma complexo, mas a relação do orçamento com outras leis orçamentárias, com destaque para a LDO, acrescidos os dispositivos previstos na LRF, não permitem dizer que o cumprimento dos objetivos do orçamento comprometeria a política econômica necessária ao melhor interesse do país, pois que o orçamento não é fechado à necessidade de adequações ao ambiente econômico. Para isso, entretanto, o Poder Legislativo não pode ser ignorado.

Para entender a flexibilidade, é necessário situá-la face a outros princípios, eminentemente jurídicos e vetores de uma boa gestão pública, que são, para a análise que aqui interessa, a transparência, a anualidade e a especificação.

\subsection{LIMITES JURÍDICOS À FLEXIBILIDADE DA EXECUÇÃo ORÇAMENTÁRIA}

\subsubsection{O princípio da transparência}

A flexibilidade se encontra em estreita conexão com o princípio da transparência. Ainda que esse seja bastante amplo e abarque uma diversidade de situações e aspectos, por ele se indica, em uma leitura que se poderia até chamar de clássica, que a projeção das receitas e das despesas deve ser estabelecida de acordo com circunstâncias 
reais, na medida em que essas se deixem prever. ${ }^{163} \mathrm{O}$ objetivo é limitar a distância existente entre os resultados esperados e efetivos da conduta orçamentária.

Outras denominações são dadas ao princípio da transparência, conforme se destaquem algumas de suas particularidades: fala-se em princípio da sinceridade, da exatidão, da veracidade e da honestidade da estimativa orçamentária. No Brasil, tem sido expresso mais consistentemente como princípio da transparência, com notável desenvolvimento a partir da LRF. Diversas orientações internacionais o aconselham, inclusive quanto ao controle de subvençôes e renúncias de receitas, que poderiam, de outra forma, ser facilmente ocultáveis. ${ }^{164}$

No art. $1^{\circ}$ da LRF estabeleceu-se que a responsabilidade na gestão fiscal pressupõe ação planejada e transparente. A previsão da publicidade como princípio da administração pública pelo art. 37 igualmente o corrobora, embora a ela não se reduza, mas há outros dispositivos específicos, tais como a previsão de que as contas dos municípios devem ficar abertas, durante 60 dias, anualmente, à disposição de qualquer contribuinte, para exame e apreciação (art. $31, \$ 3^{\circ}$ ), e pela previsão de que a lei determinará medidas para que os consumidores sejam esclarecidos acerca dos impostos que incidem sobre mercadorias e serviços (art. 150, $\$ 5^{\circ}$ ). É um princípio que vincula o Estado à sociedade, consubstanciando-se "na clareza orçamentária, na responsabilidade fiscal, no respeito aos direitos do contribuinte no aperfeiçoamento da comunicação social e no combate à corrupção dos agentes públicos" ${ }^{165}$

A exatidão das informações contidas no orçamento é também expressão nítida do princípio da unidade orçamentária, previsto pelo art. $165, \$ 5^{\circ}$, da Constituição, e que se presta fundamentalmente à transparência das informações financeiras. A inclusão das despesas e receitas no orçamento público manifesta-se pela sua perspectiva de completude. Um orçamento incompleto consiste habitualmente em estimativas imprecisas, do tipo que se observa em cálculos empurrados para baixo ou em receitas ou despesas omitidas. Apesar dessa conexão, porém, o princípio da transparência é independente do princípio da unidade. Se, por exemplo, as dotaçōes orçamentárias relativas a certas despesas forem estimadas em níveis significativamente mais altos do que as circunstâncias exigiriam, não haveria nenhuma violação ao princípio da unidade ou da completude, mas nítida discordância com o princípio da transparência.

163 NEUMARK, F. Der reichshaushaltplan: ein Beitrag zur Lehre vom öffentlichen Haushalt. Jena: Verlag von Gustav Fischer, 1929, p. 251-252.

164 INTERNATIONAL MONETARY FUND. Code of good practices on fiscal transparency. Washington: IMF, 2007.

165 TORRES, R. L. Tratado de direito constitucional, financeiro e tributário: orçamento na constituição. 2. ed. Rio de Janeiro: Renovar, 2000, v. 5, p. 209. 
Esse princípio tem grande importância para as funções que o orçamento deve cumprir. Sua inobservância compromete o equilíbrio orçamentário: as estimativas incompletas prejudicam uma relação harmônica duradoura entre receita e despesa, pois os resultados distintos obtidos provocam maior número de perturbaçōes. De um ponto de vista político, ainda, a situação financeira ao tempo da aprovação do orçamento fica encoberta tanto ao parlamento como à sociedade. A administração não apenas se retira, por meio da insinceridade, da esfera de controle parlamentar, mas também induz o Poder Legislativo a erro nas decisões políticas que precisam ser tomadas. Por exemplo, a subestimação de despesas pode convencer os parlamentares da necessidade de realização de operações de crédito; de outra parte, sua superestimação pode conduzi-los a abdicar da criação de um programa que corresponda à sua vontade, sob o argumento de que não há recursos, apenas por inconveniência à administração.

O princípio tem consequências econômicas e políticas claras. Nunca teve dificuldades em se afirmar como uma necessidade prática, porém, nem sempre encontrou suficiente tratamento teórico. Hoje, sua importância é cada vez mais ampla em razão do desenvolvimento de novos princípios de gestão aplicados ao setor público, que valorizam conceitos como a accountability e a maior participação da sociedade em políticas públicas, que podem ser estimulados pela transparência. ${ }^{166}$ A inexatidão da previsão orçamentária representa uma enorme dificuldade à prestação de contas, à análise de informações e aos controles social e de desempenho dos programas orçamentários.

Por meio da previsão reduzida das receitas ou de estimativa maior da despesa, a administração abre espaço para a criação posterior de despesas adicionais suplementares ou completamente novas. Ainda, o governo deve recorrer ao contingenciamento de despesas empenhadas caso a arrecadação se mostre insuficiente naquele determinado tempo.

Flexibilidade e transparência se implicam mutuamente, sem que haja entre elas contradição. Admitir a possibilidade de que os instrumentos de flexibilidade da execução orçamentária servissem para dar cobertura a uma previsão orçamentária insincera é incoerente com o princípio da transparência. A flexibilidade da execução orçamentária, traduzida em alterações no orçamento votado no curso do exercício financeiro em que vige, deve significar uma adaptação a situações que não puderam ser previstas ou que se fazem urgentes e imperiosas. O contrário significaria fazer da

166 ALMEIDA, C. O. F. O planejamento financeiro responsável: boa governança e desenvolvimento no estado contemporâneo. In: CONTI, J. M.; SCAFF, F. F. Orçamentos públicos e direito financeiro. São Paulo: RT, 2011, p. 595. 
flexibilidade o salvo-conduto do administrador desonesto, ou ainda transformar a habilidade em manipular dados financeiros do Estado em uma vantagem política competitiva. A flexibilidade não pode ser aí entendida como princípio oposto à transparência, mas como um instrumento de correção de erros técnicos, de adaptação à conjuntura para a realização do plano aprovado e de realização de despesas inevitáveis, no cumprimento estrito dos requisitos que a Constituição e a legislação orçamentária lhe impõem. A transparência orçamentária, além disso, permite saber com mais clareza a produtividade e a eficiência do gasto, podendo servir a sua redução. Pode indicar, portanto, se acréscimos nas dotações durante a execução são realmente necessários. ${ }^{167}$

\subsubsection{O princípio da especialidade}

O princípio da especialidade (ou da especificação, ou da especialização) do orçamento público é habitualmente tratado em seu aspecto material. Deve-se reconhecer, entretanto, que o conceito de especialidade para o orçamento (em particular para a execução orçamentária) tem duplo desdobramento, tanto material como temporal.

A simples norma que estabelece que o orçamento vale para um exercício financeiro expressa um tipo de especialidade temporal, que faz com que o orçamento seja intrinsecamente específico. Isso o reconheceu, em trabalho bastante antigo, Boiteau: "o orçamento é, em si mesmo, uma primeira especialidade". ${ }^{168}$ Ao lado desse aspecto temporal, encontra-se também especialidade material nos casos em que se deseja que as estimativas orçamentárias da imensa quantidade de operações financeiras de uma comunidade política adquiram articulação e ordem. No lugar da multiplicidade arbitrária, busca-se a escolha racional de fins; somente poderão ser executadas aquelas despesas que tiveram sua estimativa discriminada no orçamento. Os meios públicos devem ser empregados não em montantes aleatórios, mas de acordo com a maneira pela qual determinada quantidade de dinheiro foi alocada para um fim específico.

\subsubsection{A especialidade temporal: o exercício financeiro e atenuações ao princípio da anualidade da despesa}

Está disposto no art. $165, \$ 9^{\circ}$ da Constituição que lei federal disporá sobre o exercício financeiro. A Lei n. 4.320/64, posto que seja anterior ao texto constitucional

167 RUBINSTEIN, F. Notas Sobre a transparência fiscal no direito financeiro. CONTI, J. M.; SCAFF, F. F. Orçamentos públicos e direito financeiro. São Paulo: RT, 2011, p. 880.

168 BOITEAU, P. Budget général de l'etat. In: SAYS, L. Dictionnaire des finances. Paris: Berger-Levrault, 1889, v. I, p. 611, tradução livre. 
vigente, disciplina o comando mencionado. Seu art. 34 estabelece que o exercício financeiro coincidirá com o ano civil.

Um levantamento feito por James Giacomoni expõe detalhadamente as inúmeras alteraçôes que sofreu o exercício financeiro no Brasil, nem sempre coincidindo com o ano civil. Sua superposição, porém, foi reafirmada pela Lei n. 4.320/64, a qual consolidou a regra prevista na lei anterior. ${ }^{169} \mathrm{O}$ percurso cronológico demonstra que a realização de operações de receita e despesa pode não seguir, e dificilmente segue, a previsão inicial contida na lei de orçamento. Essa margem de imprecisão levou a legislação financeira brasileira, em diversos momentos da sua história, a prolongar o exercício financeiro em relação ao ano civil para possibilitar que lançamentos retardatários de receita ou despesas empenhadas, mas ainda não pagas, pudessem ocorrer posteriormente, em um sistema contábil mantido em aberto por mais tempo. Atualmente, ainda que não se preveja a prorrogação do exercício, ocorre efeito parecido, na prática, mediante a inscrição de restos a pagar no orçamento do ano seguinte, conforme trata o art. 36 da Lei n. 4.320/64. Pelo princípio da continuidade dos serviços públicos, as obrigações ainda não pagas transferem-se ao exercício seguinte e oneram, em certa medida, o próximo orçamento. Isso do lado da despesa. No âmbito das receitas, também elas não se costumam comportar como o previsto, podendo ser lançadas em determinado exercício financeiro, mas nele não efetivamente recebidas. Nesse caso, são inscritas como dívida ativa (art. 39, Lei n. 4.320/64). Observa-se, assim, a característica flutuante do ambiente orçamentário, submetido às variações conjunturais da realidade econômica e à adaptação da programação administrativa a elas. Nesse sentido, o princípio da anualidade também não é compreendido em termos absolutos, mas admite que receitas e despesas de um exercício tenham seus efeitos prolongados sobre outros. A inclusão dos restos a pagar e da dívida ativa no orçamento, porém, reforça a necessidade de que haja transparência quanto a tais informações, para que se saiba quanto do orçamento de um ano está comprometido pela inexecução do orçamento anterior: a flexibilidade existe aí, como se nota, para preservar o conhecimento e o controle parlamentares sobre a atividade financeira pública. Do contrário, caso o tema da execução fosse assunto restrito exclusivamente ao Poder Executivo, não seria necessário que despesas e receitas aprovadas em um ano fossem novamente conduzidas à apreciação parlamentar. Fosse o orçamento nada mais que uma autorização conferida, problema algum haveria em seu não cumprimento efetivo, desde que uma vez aprovado.

169 GIACOMONI, J., cit., p. 296 e ss. 


\subsubsection{A especialidade material: aspectos quantitativo e qualitativo}

A partir dessas considerações, e no interesse da especialidade material do orçamento público, as previsões das despesas orçamentárias devem ser, tanto quanto à destinação como quanto ao montante, observadas pelos órgãos encarregados de executar o orçamento. Qualitativamente, a especialidade significa a definição das finalidades. Quantitativamente, refere-se aos créditos orçamentários, isto é, às verbas estabelecidas para cada programa.

\subsection{Especialidade qualitativa}

O princípio da especialidade qualitativa do orçamento público, ocasionalmente também referido como princípio da dotação, prescreve que os objetivos definidos pelo orçamento apenas podem receber os recursos a eles alocados. É inadmissível, por consequência, que um crédito orçamentário se destine, total ou parcialmente, a despesa não prevista, ou que tenha aplicaçôes em finalidades diferentes daquelas às quais foi designado.

Esse princípio tem grande significado tanto em sentido financeiro como político. De nada adiantaria ser o orçamento completo e transparente, estimado com a maior precisão possível, aprovado regularmente e assim por diante, se os órgãos responsáveis por sua execução tivessem toda liberdade de empregar os meios previstos em programas diferentes daqueles aprovados, assim como mover livremente eventuais saldos e economias, ou de transferir sobras de despesas anuladas ou suficientemente cobertas para outros títulos, como bem lhes aprouvesse. As chances de o orçamento atingir os fins para os quais ele foi aprovado estariam, nesse caso, seriamente comprometidas e o rito de aprovação parlamentar não teria qualquer função. Politicamente, o parlamento não teria influência sobre o orçamento. Sob o ponto de vista financeiro, esse processo de sucessivas alterações arbitrárias teria o resultado de que o planejamento orçamentário seria substituído pela aleatoriedade das decisões ocasionais.

No que concerne às condições de realização desse princípio, tem-se que ele depende de condiçôes objetivas e subjetivas, conforme exposto por Neumark. ${ }^{170}$

Como condição objetiva, os créditos orçamentários devem ser altamente delimitados. Dado que existe uma estreita conexão entre a especialidade qualitativa e a transparência, essa depende decisivamente do grau de aplicação daquela. Mas isso não significa que, no interesse da transparência, deve-se seguir até as últimas consequências

170 NEUMARK, F. Der reichshaushaltplan: ein Beitrag zur Lehre vom öffentlichen Haushalt. Jena: Verlag von Gustav Fischer, 1929, p. 299 e ss. 
as minudências de cada programa, ficando os agentes encarregados por ela impossibilitados de realizar os detalhes não previstos. Antes disso, o princípio significa que se tornam juridicamente vinculantes apenas as partes dos créditos orçamentários que sejam suficientes para esclarecer, de maneira clara, sua finalidade.

Exigência subjetiva é que o Poder Executivo não se afaste da finalidade dos créditos orçamentários. O cumprimento voluntário dessa condição é, na prática, raro, porque cada órgão da burocracia administrativa apresenta a tendência de querer agir tão autonomamente quanto possível. Como as administrações dificilmente têm o poder de aprovar um orçamento apenas com dotaçóes globais ou fundos conjuntos, sistemas de flexibilidade são, em alguns sistemas, pensados para permitir transferências entre programas, abrindo-se uma exceção ao princípio da especificação (tais como os tradicionais virements do direito orçamentário francês).

De qualquer maneira, a especialidade qualitativa apenas tem alguma utilidade prática se sua observância é garantida por instituições de controle. Sem normas e órgãos encarregados de verificar sua aplicação, a aplicação voluntária dos recursos da maneira como aprovados é uma expectativa irreal.

\subsection{Especialidade quantitativa}

De acordo com o princípio da especialidade quantitativa do orçamento, as despesas apenas podem ser realizadas com o montante de recursos previstos para elas. Consequentemente, por esse princípio não se admitem despesas que extrapolem ou que criem novas dotações orçamentárias. Seria ilógico que essa formulação caracterizasse apenas o último ato do processo de realização da despesa, que é seu pagamento, como ilegítimo, se ele ultrapassasse ou se fizesse por dotação nova. Portanto, estende-se a todos os atos administrativos anteriores pelos quais se processo o dever jurídico de pagamento, tais como o empenho e a liquidação, a seguir expostos.

Ao se abrirem créditos adicionais ao orçamento, sob a modalidade de suplementação ou de criação de novo programa, frequentemente os documentos governamentais fazem referência a alterações quantitativas e qualitativas, respectivamente. Desse modo, os créditos suplementares seriam alteraçõos quantitativas, ao passo que os especiais seriam qualitativas. Essa diferenciação se baseia na ideia de que, no primeiro caso, somente a especialidade do montante de recursos dotados é afetada, ao passo que, no outro, trata-se de uma alteração na natureza da finalidade definida. Neumark afirma que o cerne dessa separação conceitual é correto, mas a classificação não parece ser útil. Nos dois casos, será criada uma despesa adicional, representando sempre uma maior carga ao orçamento público. ${ }^{171}$ Ocorre que essa não

171 NEUMARK, Der reichshaushaltplan: ein Beitrag zur Lehre vom öffentlichen Haushalt, cit., p. 311. 
é uma consideração generalizável. Em sistemas jurídico-orçamentários tais como o brasileiro, que especificam não apenas a modalidade de crédito, mas também a origem dos recursos, nem sempre se pode afirmar que as despesas aumentam com a abertura de crédito adicional, pois que em alguns casos os recursos admitidos são aqueles provenientes da anulação de outras despesas. O mais provável é que o caso a que se refere o jurista alemão não seja exatamente aquele enquadrado no conceito de crédito adicional, mas de transferências, remanejamentos e transposições.

Esse princípio tem significativa importância para a manutenção das prerrogativas parlamentares de aprovação do orçamento, também dependendo de significativo controle para sua concretização, para controlar eventuais tentações do Poder Executivo. Em razão disso, as alterações na quantidade dos créditos apenas podem ser feitas em conformidade com o que disciplinem as normas aplicáveis. No sistema brasileiro, há tanto normas constitucionais como legais a respeito. Se as próprias normas constitucionais, porém, estabelecem possibilidades tão largas de flexibilização, como a previsão de uma autorização prévia para aberturas de créditos adicionais em limites não definidos, não é possível esperar que o respeito democrático ao orçamento aprovado seja feito por boa vontade do administrador, quando lhe é dada a legítima possibilidade de lançar mão dos mais diversos expedientes de mudá-lo sem qualquer ameaça de devido contrapeso do parlamento. Nesse caso, é de se esperar normas mais restritivas para contornar este quadro.

Uma das alternativas apontadas é que as necessidades impostergáveis de despesas adicionais sejam de alguma forma incorporadas ao orçamento, por exemplo, por meio da previsão de uma reserva de contingência. A finalidade não é apenas política, mas também econômica, pois permite maior comparação entre despesas e receitas. De um lado, é impossível planejar em cada caso concreto uma estimativa orçamentária para despesas imprevistas. Isso seria um grande encargo tanto ao parlamento como à administração, sem que se garantissem resultados palpáveis. Em vista dessas considerações, as necessidades não previstas no orçamento original e que não podem esperar sua satisfação até o próximo exercício financeiro devem ser estimadas e aprovadas por lei. Para tanto, há principalmente duas alternativas à disposição de um sistema jurídico orçamentário, que são: a revisão completa do orçamento público no decorrer do exercício financeiro; as alterações específicas, feitas caso a caso. À primeira denomina-se comumente orçamento retificativo; as outras correspondem aos créditos adicionais. Ambos são meios juridicamente legítimos, na medida em que previstos pelas normas jurídicas de um dado sistema.

\subsection{A EXECUÇÃO DO ORÇAMENTO BRASILEIRO: DO REGISTRO DOS CRÉDITOS AO PAGAMENTO}

Será feita, nesse ponto, uma descrição das formas jurídicas mais relevantes para os procedimentos administrativos da execução da despesa pública, dando-se destaque 
para algumas etapas anteriores, referentes à especificação dos créditos orçamentários. A finalidade é estabelecer a relação entre a execução da despesa e o crédito que a prevê, assim como o caráter especial dos instrumentos de flexibilidade, que devem vir a ser adotados diante de circunstâncias específicas, e não são, pois, uma prerrogativa geral dos órgãos responsáveis pela execução, como se houvesse alguma forma de direito subjetivo público do Poder Executivo a alterar o orçamento.

\subsubsection{O orçamento analítico como expressão da especialidade orçamentária}

A expressão "orçamento analítico" costuma ser usada, no Brasil, para se referir à maneira de inclusão das receitas e despesas no orçamento e a seu grau de especialidade. Abrange, portanto, o princípio da especialidade, embora não distinga, claramente, entre seus aspectos qualitativo e quantitativo anteriormente apontados. Sob o ponto de vista jurídico, falar em orçamento analítico significa fazer referência às normas que determinam o detalhamento e a extensão do orçamento, conforme a legislação específica que discipline a matéria em cada unidade da federação. A especificação e o modo de sua organização contábil são fundamentais para a execução, determinando a forma de seu exercício. Normalmente, também diz respeito a quadros que discriminam, como for possível e conveniente, a classificação das despesas e das receitas. Representada no art. $5^{\circ}$ da Lei n. 4.320/64, que repugna as despesas globais, essa ideia traduz, no sistema orçamentário brasileiro, ora a previsão de que as dotações se destinem apenas à finalidade para a qual foram previstas (aspecto qualitativo), ora a que apenas sejam executadas nos montantes autorizados (aspecto quantitativo). Embora não seja feita essa discriminação, o objetivo é inequívoco: que haja condições ideais de fiscalização pelo parlamento, além do fato de que essa especificação inibe que as atividades governamentais se expandam muito além dos créditos detalhadamente aprovados. ${ }^{172} \mathrm{O}$ problema mais sério, diagnosticou José Afonso da Silva, ${ }^{173}$ é "saber qual o limite da discriminação, pois não deverá haver descrição minuciosa nem globalização. Na técnica do orçamento-programa, a especialização se traduz, em primeiro lugar, na classificaçáo dos recursos e das despesas, e, depois, dentro de cada classe é que se realiza a discriminação.”

Nesse ponto, é relevante destacar a existência da preocupação com uma especificação paralisante da execução orçamentária, apontada no excerto anteriormente e desenvolvida por Giacomoni: ${ }^{174}$ "não cabe transformar as unidades executoras em

172 GIACOMONI, cit., p. 82.

173 SILVA, Orçamento-programa no Brasil, p. 255.

174 GIACOMONI, cit., p. 263-264. 
reféns de uma programação orçamentária excessivamente detalhada, especialmente quando a retificação desta programação depende de demorados procedimentos burocráticos e legais."

A especialização se traduz, no orçamento-programa, pela classificação de receitas e das despesas, e esses são discriminados dentro de cada classe. $\mathrm{O}$ art. 11 da Lei n. 4.320/64 determina a classificação de receitas em correntes e de capital e o art. 12 o faz quanto às despesas, também classificadas em despesas correntes (despesas de custeio e transferências correntes) e despesas de capital (investimentos, inversões financeiras e transferências de capital). Cada um desses itens, que constituem a respectiva classe, encontra sua definição na legislação. Essas são as chamadas categorias econômicas de classificação. Dentro de cada uma delas é feita a discriminação da despesa "por elementos, em cada unidade administrativa ou órgão de Governo” (art. 13, Lei n. 4.320/64), conforme o extenso esquema delineado neste dispositivo. De acordo com o art. 15 da mesma lei, a discriminação deve ser feita, no mínimo, por elementos, admitindo-se, porém, especificações mais minuciosas.

Cumpre ressaltar que a classificação de receitas e despesas em categorias econômicas não basta para que se atenda ao princípio da especificação, devendo-se discriminá-las dentro das instituições, no nível global das diversas categorias orçamentárias (programa, subprograma, atividade, projeto e obra) e, em muitos casos, segundo uma distribuição geográfica ou regional.

Dizendo de maneira ampla, o conhecimento dos resultados da gestão patrimonial depende da classificação das contas. A classificação contribui para a efetiva execução do orçamento, facilita a formulação de programas e a prestação de contas e torna possível a análise dos efeitos econômicos das atividades governamentais.

\subsubsection{Registro dos créditos e dotações}

O modelo analítico de orçamento opera por meio registro dos créditos orçamentários e das dotações, para que se possa acompanhar o andamento de seus saldos e, mais amplamente, da programação do governo. ${ }^{175}$ Aqui, também a disciplina do registro serve tanto a fins quantitativos (pois permite conhecer a classificação e o título apropriado em que cada despesa deve ser lançada) como qualitativos (com a possibilidade de que os montantes de cada uma das dotaçôes fiquem evidenciados).

Como ressalva prévia ao tema, aponta-se uma comum confusão terminológica entre créditos orçamentários e dotações. Giacomoni ${ }^{176}$ e Machado Jr. e Heraldo

\footnotetext{
175 Cf. GIACOMONI, cit., p. 265.

176 GIACOMONI, cit., p. 265.
} 
Reis ${ }^{177}$ os distinguem, dizendo que dotação "deve ser a medida, ou quantificação monetária do recurso aportado a um programa, atividade, projeto, categoria econômica ou objeto de despesa" ${ }^{178} \mathrm{O}$ crédito orçamentário é "a autorização através da lei de orçamento ou de créditos adicionais para a execução de programa, projeto ou atividade ou para o desembolso de quantia aportada a objeto de despesa, vinculado a uma categoria econômica, e, pois, a um programa". Portanto, o crédito orçamentário contém uma dotação.

A Lei n. 4.320/64 apresenta as seguintes categorias classificatórias que constituem o crédito orçamentário: elemento, subcategoria econômica, categoria econômica, projeto ou atividade, subprograma, programa, função, unidade orçamentária e órgão. Dada a relevância da concepção de orçamento-programa para o sistema orçamentário vigente, convém destacar a incorporação, pela referida lei complementar, por meio de seu Anexo n. 5, da classificação funcional-programática, que havia sido adotada pelo orçamento federal a partir de 1968. Essa classificação é o antecedente da classificação por programas, adotada nos orçamentos federais a partir de 1999. Absorvida pela lei complementar, a classificação funcional-programática valeu como norma geral que se deve aplicar aos orçamentos das diversas entidades federativas. São cinco as categorias por ela escorçadas: função, programa, subprograma, projeto e atividade, em ordem crescente de especialidade. A Portaria n. 9/74 (que acabou transformada no citado Anexo 5) define projeto e atividade. Projeto é o "instrumento de programação para alcançar os objetivos de um programa, envolvendo um conjunto de operações limitadas no tempo, das quais resulta um produto final que concorre para a expansão ou o aperfeiçoamento da ação do governo." De outro lado, a atividade é "um instrumento de programação para alcançar os objetivos de um programa, envolvendo um conjunto de operaçóes que se realizam de modo contínuo e permanente, necessárias à manutenção da ação do governo". Daí se entende que se o programa, que compreende projetos, atividades e operações especiais, é o objetivo a se atingir com a execução do orçamento, acaba sendo ele também definido como a categoria mais importante. Além disso, "funções são, então, constituídas pela divisão, em grandes linhas, das áreas de atuação do governo. Os subprogramas são partes dos programas; representam objetivos parciais buscados pelo governo por meio do orçamento". ${ }^{179}$

A partir dessa orientação normativa, adotou-se a classificação por programas, que tem o objetivo de vincular as despesas aos resultados pretendidos. Essa classificação

177 MACHADO Jr.; REIS, cit., p. 20.

178 MACHADO Jr.; REIS, cit., p. 20.

179 GIACOMONI, cit., p. 100. 
é exigência legal no Brasil desde que a Lei n. 4.320 determinou que a lei orçamentária "conterá a discriminação da receita e despesa, de forma a evidenciar a política econômico-financeira e o programa de trabalho do Governo" (art. 2o).

A partir de 1990, conforme determinação da Lei de Diretrizes Orçamentárias então vigente, alterou-se a noção de classificação conforme a natureza da despesa, que envolvia a obrigatoriedade de discriminar a despesa até o nível de elementos. Tal determinação foi estendida a outras unidades da federação a partir do exercício de 2002, por meio de Portaria Interministerial, que pôde introduzir tal norma geral a partir do disposto no art. 50, $\$ 2^{\circ}$, da Lei Complementar n. 101/2000. ${ }^{180}$ Mantiveram-se as categorias econômicas e criaram-se grupos de despesa e o conceito de modalidade de aplicação. O art. $6^{\circ}$ da Portaria Interministerial STN/SOF 163/2001, entretanto, permitiu excluir o item "elementos" da lei orçamentária, dispondo que, nela, a discriminação da despesa será feita, quanto à sua natureza, no mínimo, por categoria econômica, grupo de natureza de despesa e modalidade de aplicação. Trata-se de norma cujo teor é claramente contrário ao art. 15 da Lei n. 4.320/64, que prevê a classificação da despesa, segundo sua natureza, no mínimo por elementos. Como essa é uma lei complementar, não é possível que seja alterada por portaria, mesmo que se trate do exercício de competência prevista pelo art. 50, $\$ 2^{\circ}$, da LRF.

Esse dispositivo da Lei n. 4.320/64 é um ponto crítico da lei geral do orçamento, exatamente por sua rigidez. Com um sistema classificatório que esmiúça a despesa no orçamento até o nível dos elementos, ficam esses indissociáveis da subcategoria econômica, item mais abrangente no qual se incluem, podendo-se vislumbrar dificuldades quanto à discriminação adequada na elaboração e no acompanhamento da execução orçamentária.

A Portaria Interministerial STN/SOF 163/2001, modificada por sucessivas portarias, teve a finalidade de resolver dificuldades como estas, combinando categorias econômicas, grupos, modalidades de aplicação e elementos. Permitiu que esses últimos estivessem presentes em diversos grupos. Um problema, porém, permanece: despesas com pessoal devem ainda ser classificadas como pessoal e encargos sociais, vinculando-se necessariamente às despesas correntes.

Relacionando o registro dos créditos com a ideia de orçamento analítico, expressões do princípio da especificidade, o detalhamento orçamentário se costumava

180 Esse artigo dispõe que "a edição de normas gerais para consolidação das contas públicas caberá ao órgão central de contabilidade da União, enquanto não implantado o conselho de que trata o art. 67". A STN exerce a competência temporária de "órgão central de contabilidade da União". 
realizar por meio do Quadro de Detalhamento de Despesa (QDD), que cada Poder e o Ministério Público elaboravam no seu respectivo âmbito de atuação. Feita a citada reorganização da classificação da despesa conforme a natureza, adotando-se as categorias econômicas, grupo, modalidade de aplicação e elemento, apenas os grupos de despesa constavam da lei orçamentária. As demais vinham no QDD, o que conferia ao Executivo grande poder de disposição sobre os créditos orçamentários, pois a aprovação do orçamento pelo Congresso se dava em termos mais genéricos e era o governo que elaborava o quadro de detalhamento. Por emendas à Lei n. 9.692/98 (Lei de Diretrizes Orçamentárias para o exercício de 1999), o Congresso Nacional determinou que apenas a categoria "elementos" não constasse da lei orçamentária. Todas as outras deveriam estar ali referidas. Há, assim, maior transparência na lei orçamentária.

Por outro lado, e antes da alteração citada anteriormente, o QDD apresentara certos inconvenientes ao Poder Executivo, que o alterou em alguns aspectos. Os inconvenientes alegados se resumem à falta de agilidade da execução da despesa quando se tem que elaborar e publicar constantemente o QDD, além de ser necessário fazer constar nele as alterações da classificação verificadas durante o exercício. Tentando afastar tais empecilhos, a LDO para o exercício de 1997 (Lei n. 9.293/96, art. 56, caput, e art. $3^{\circ}$ ) determina que apenas o QDD inicial seja publicado. As alterações necessárias devem ser feitas diretamente no Sistema Integrado de Administração Financeira (SIAFI), em que ocorre o procedimento de detalhamento do orçamento.

Revela-se, por isso, que o registro dos créditos orçamentários, ainda que deva atender ao princípio da especificidade, classificando a despesa em diversas categorias e níveis de detalhamento, depara-se com certo grau de maleabilidade da classificação. É evidente, entretanto, que a necessidade de flexibilidade na fase de execução do orçamento se deve coadunar com o princípio da legalidade, bem como do controle parlamentar. Os créditos devem ser tão específicos quanto o possam. Por outro lado, não tão específicos a ponto de não admitir qualquer alteração. ${ }^{181}$ Nesse sentido, a iniciativa do SIAFI é adequada por permitir que na lei orçamentária conste classificação suficiente, de maneira que chegue à cognição parlamentar o conteúdo correto da despesa apreciada, e, ao mesmo tempo, por possibilitar que detalhamentos maiores, no patamar de elementos, sub-elementos e itens, dispensáveis de tomar grande tempo do processo político de aprovação do orçamento, sejam feitos diretamente em um sistema ágil, de toda forma transparente e aberto ao controle.

181 Le Gouvernment doit être lié mais non ligoté (GAUDEMET, P.-M.; MOLINIER, J. Finances publiques. 7. ed. Paris: Montchrestien, 1996, v. 1, p. 100). 


\subsubsection{Programação financeira e cronograma de desembolso}

A previsão orçamentária das receitas e despesas, de acordo com o princípio da anterioridade, não tem por consequência que a execução das operações de arrecadação e dispêndio fique submetida a uma obrigação de conformidade absoluta, o que seria impossível. Essa obrigação é mais restritiva quanto às receitas, mas não por força da previsão orçamentária, que há muito não vige o princípio da anualidade tributária, e, sim, por decorrência do princípio da legalidade: o ato de arrecadação que não encontre seu fundamento em norma válida é reputado nulo. Além disso, como a instituição de tributo é matéria de competência legislativa, a administração não pode, no momento da execução, modificar a lei tributária ou apreciar a conveniência e a oportunidade da arrecadação, pelo que o tributo, conforme a dicção do art. $3^{\circ}$ do Código Tributário Nacional, é cobrado mediante atividade administrativa plenamente vinculada. No que concerne não ao tipo, mas ao montante da previsão do tributo, o orçamento fornece uma estimativa. Nesse ponto, a autorização orçamentária é ainda menos constritiva, porque é uma autorização ilimitada, o Estado pode arrecadar mais do que o volume previsto, desde que exerça suas competências nos termos das normas em vigor.

Em relação à estrita obrigação de execução que prevalece quanto às receitas, a qual não decorre da previsão orçamentária, mas de outras normas jurídicas, a execução da despesa tem uma margem de apreciação significativamente maior. A lei orçamentária institui faculdades de utilização de créditos, estabelecendo limites máximos nas suas dotaçōes, visto que a Constituição proíbe a concessão de créditos ilimitados (art. 167, VII). A inscrição de créditos na lei orçamentária é uma condição necessária para que a despesa seja regularmente executada; é necessário, no entanto, relacionar a despesa à arrecadação.

Especificadas as despesas que deverão ser executadas no exercício financeiro posterior àquele de sua inclusão na proposta orçamentária, a administração se depara com uma questão essencial à adequada gestão dos recursos: o ritmo em que esses deverão ser gastos. O planejamento do tempo de liberação do dinheiro público é instrumentalizado pela programação financeira e pelo cronograma do desembolso, que serão estabelecidos pelo Poder Executivo, nos termos do art. $8^{\circ}$ da Lei Complementar n. 101/2000, após 30 dias da publicação dos orçamentos, de acordo com o que disponha a LDO. Trata-se de disposição paralela às quotas trimestrais da despesa previstas pela regra anterior, contida nos arts. 47 a 50 da Lei n. 4.320/64. O Decreto-Lei n. $200 / 67$, no art. $7^{\circ}, d$, trata a programação financeira do desembolso como instrumento básico do planejamento da ação governamental. 
Essa programação tem a função de "ajustar o ritmo de execução do orçamento-programa ao fluxo provável de recursos", de maneira a "assegurar a liberação automática e oportuna dos recursos necessários à execução dos programas anuais de trabalho" (art. 17, Dec.-Lei 200/67). Somente em consonância com a programação financeira do desembolso é que compromissos financeiros poderão ser assumidos (art. 18, idem).

Em linhas gerais, a programação de desembolso existe porque a entrada de receitas e o pagamento das despesas não ocorrem nem ao mesmo tempo, nem no volume necessário para as diferentes ocasióes. Cabe ao governo planejar seus gastos de acordo com o fluxo dos recursos que ingressam em sua contabilidade. É um importante instrumento de racionalização da liberação, às unidades orçamentárias, dos recursos necessários à execução dos programas de trabalho. Essa programação se caracteriza por três objetivos fundamentais:

ajustar o ritmo de execução do orçamento ao fluxo provável de recursos, assegurar a entrega automática às unidades orçamentárias, em tempo hábil e dentro dos limites previamente estabelecidos, da soma de recursos financeiros necessários e suficientes à execução dos seus programas, e manter, durante o exercício, na medida do possível, o equilíbrio entre a receita e a despesa realizada, de modo a reduzir ao mínimo eventuais insuficiências de tesouraria. ${ }^{182}$

O desembolso deve ocorrer de forma a considerar o fluxo das receitas. Cabe ao Poder Executivo elaborar o cronograma mensal de desembolsos (art. 8º, Lei Complementar n. 101/2000), incluindo, na fixação das quotas mensais, também os créditos adicionais e as operações extra orçamentárias, particularmente os restos a pagar (art. 49, Lei n. 4.320/64). Com esse dispositivo de inclusão na programação de outras operações de natureza financeira, procurou-se disciplinar o fluxo de caixa tomando em consideração

as disponibilidades existentes; a afluência provável da receita própria e de receitas transferidas; o orçamento aprovado, com a discriminação por unidades orçamentárias; outros débitos ou compromissos, como os oriundos de créditos especiais abertos nos últimos quatro meses do exercício recém-encerrado; os restos a pagar; os compromissos da dívida pública e outros dessa natureza; e outros compromissos e circunstâncias que possam influir no comportamento efetivo das receitas e na realização da despesa. ${ }^{183}$

Com essa extensão se refere o dispositivo legal aos créditos adicionais e operações extra orçamentárias.

182 SILVA, Orçamento-programa no Brasil, cit.

${ }^{183}$ MACHADO Jr., J. T.; REIS, H. C. A Lei n. 4.320 comentada e a Lei de Responsabilidade Fiscal. 31. ed. Rio de Janeiro: Ibam, 2002/2003, p. 126. 
Faz parte desse dispositivo a ideia de que a programação é um processo contínuo da administração. Feita a programação inicial no orçamento, que é aprovada como determinado plano de trabalho, ela deve começar a ser executada também de forma planejada. Para evitar que a administração atue de modo a concentrar todas as despesas nos primeiros meses do ano, quando a tesouraria arrecadou apenas pequena parte dos recursos, adotava-se anteriormente o regime dos duodécimos como medida central para planejar o ritmo da execução, pelo qual a despesa era dividida em doze partes iguais, correspondentes a cada mês do ano. Em cada período mensal se poderia utilizar 1/12 da dotação prevista. Distribuía-se a despesa ao longo do ano. É o modo de execução atualmente vigente, por exemplo, em Portugal. ${ }^{184}$ Esse tipo de programação, todavia, é problemático por estabelecer limites mensais para a execução do programa da administração: o sistema funciona bem com relação às despesas fixas, notadamente de pessoal, mas é inoportuno para, por exemplo, a compra de materiais ou outra despesas que não se executam de forma uniformemente distribuída no tempo. ${ }^{185}$ É mais adequado que as cotas mensais sejam estabelecidas conforme um programa, atendendo-se à peculiaridade de cada tipo de despesa.

O art. 13 da LRF prescreve, ainda, que no prazo de trinta dias após a publicação dos orçamentos, as receitas previstas sejam desdobradas, pelo Poder Executivo, em metas bimestrais de arrecadação, com a especificação, em separado e quando cabível, das medidas de combate à sonegação e à evasão da quantidade e valores de ações ajuizadas para cobrança da dívida ativa, bem como da evolução do montante dos créditos tributários passíveis de cobrança administrativa.

Em suma, a programação é flexível e pode ser alterada durante o exercício financeiro, o que, demais, se prevê no art. 50 da Lei n. 4.320/64. As cotas mensais poderão ser alteradas durante o exercício, desde que observados o limite da dotação e o comportamento da execução orçamentária. De modo a contornar os problemas do rígido sistema dos duodécimos, preparou-se, então, um sistema flexível de execução apto a atender às circunstâncias reais que se apresentem conforme o desenvolvimento da relação entre receita e despesa.

Vê-se que as cotas de desembolso são fixadas conforme evolua a arrecadação de receitas, que é elemento variável. É necessário que exista a possibilidade, então, de alterar a programação financeira estabelecida, como menciona José Afonso da Silva. ${ }^{186}$ E não é apenas o comportamento da entrada de recursos que pode justificar a alteração da programação, senão, também, as modificações nas prioridades

184 RIBEIRO, J. J. T. Liçôes de finanças públicas. 5. ed. Coimbra: Coimbra Editora, 1997, p. 117.

185 Cf. MACHADO Jr.; REIS, cit., p. 122.

186 SILVA, Orçamento-programa no Brasil, cit., p. 328. 
políticas expressas no orçamento, ${ }^{187}$ definidas entre os Poderes Executivo e Legislativo. Ademais, o art. $9^{\circ}$ da Lei de Responsabilidade Fiscal dá comandos para a revisão da programação do desembolso, que deve ocorrer: no caso de restabelecimento da receita prevista, ainda que parcial, recompondo-se as dotaçôes cujos empenhos foram limitados de forma proporcional às reduçōes efetivadas; e ao final do bimestre, se for verificado que a realização da receita poderá não comportar o cumprimento das metas de resultado primário ou nominal estabelecidas no Anexo de Metas Fiscais. Nesse caso, os Poderes do Estado e o Ministério Público promoverão por ato próprio e nos montantes necessários, nos trinta dias subsequentes, limitação de empenho e movimentação de receita (o chamado contingenciamento de recursos), segundo critérios fixados pela LDO.

\subsubsection{Estágios da despesa: empenho, liquidação e pagamento}

Definido o empenho no art. 58 da Lei n. 4.320/64 como o ato emanado de autoridade competente que cria para o Estado obrigação de pagamento pendente ou não de implemento de condição, há algumas outras funções por ele cumpridas no controle da execução do orçamento. Trata-se do ato administrativo ao qual cabe enquadrar a despesa em determinado crédito orçamentário, deduzindo-a. Funciona, além disso, como uma garantia ao credor de que os valores empenhados têm respaldo orçamentário. ${ }^{188}$

Como ato cuja finalidade principal é reservar recursos para posterior pagamento, o empenho se mostra uma das etapas mais importantes pela qual passa a despesa pública. Ele evita que o pagamento seja frustrado por falta de verba e ao mesmo tempo possibilita aos diversos órgãos do governo conhecer as diversas parcelas empenhadas da despesa. Ressalta-se, todavia, que a prática administrativa brasileira muitas vezes adota o empenho a posteriori, apenas a pretexto de cumprir formalmente a legislação pertinente. Trata-se de um problema de planejamento e de deficiências de programação. ${ }^{189}$

Por outro lado, o art. 68 estabelece o chamado regime de adiantamento, ao qual o art. 65 se referira como aplicável a casos excepcionais. Conforme o art. 68, o regime de adiantamento é aplicável aos casos expressamente definidos em lei e consiste na entrega de numerário a servidor, sempre precedida de empenho na dotação própria, para o fim de realizar despesas que não possam subordinar-se ao processo

187 SILVA, Orçamento-programa no Brasil, cit., p. 265.

188 GIACOMONI, J. Orçamento público. 13. ed. São Paulo: Atlas, 2005, p. 270.

189 MACHADO Jr.; REIS, cit., p. 144. 
normal de aplicação. Há casos em que os recursos destinados a determinada despesa são empenhados antes que a própria despesa seja pactuada, desde que haja previsão expressa em lei. A previsão desse regime em caráter de exceção confirma, porém, a necessidade de empenho ex ante, mesmo em casos de despesas especiais.

Processado o empenho, segue-se à liquidação. De acordo com o art. 63 da Lei n. 4.320/64, a liquidação consiste na verificação do direito adquirido pelo credor, tendo por base os títulos e documentos comprobatórios do respectivo crédito. É a verificação de que a despesa anteriormente empenhada é legítima, com a finalidade de apurar a origem e o objeto do que se deve pagar, a importância exata e a quem se deve pagar a importância, para extinguir a obrigação (art. 63, $\$ 1^{\circ}$, I, II e III).

Se a liquidação é ato de verificação do direito adquirido pelo credor ao recebimento da prestação, não se pode falar, ainda, que é com esse ato que se cria à administração a obrigação de pagar. As cláusulas contratuais devem ter se verificado cumpridas. ${ }^{190}$ Por esse motivo, contratos de obras e de prestação de serviços em que se estipula o adiantamento de pagamentos devem ser feitos com cuidado, de modo a evitar que a obra ou o serviço sejam implementados fora das condições exigidas ou que, simplesmente, não sejam realizados de modo algum. Nesse sentido, a liquidação não é simplesmente ato formal de verificação do direito adquirido pelo credor, mas deve refletir a realidade:

[h] á um ponto central a considerar: é [a liquidação] a verificação objetiva do cumprimento contratual. A fase de liquidação deve comportar a verificação in loco do cumprimento da obrigação por parte do contratante. Foi a obra, por exemplo, construída dentro das especificaçōes contratadas? Foi o material entregue dentro das especificações estabelecidas no edital de concorrência ou de outra forma de licitação? Foi o serviço executado dentro das especificaçōes? O móvel entregue corresponde ao pedido? E assim por diante. Trata-se de uma espécie de auditoria de obras e serviços, a fim de evitar obras e serviços fantasmas. (...) O documento de liquidação, portanto, deve refletir uma realidade objetiva. ${ }^{191}$

As condições previstas na licitação, no contrato, no empenho ou em outro ato administrativo fundamental da relação jurídica em questão, devem ser observadas.

Verificado, pela liquidação, o direito adquirido pelo credor, a autoridade competente exara, por despacho, a ordem de pagamento. Por esse se determina que a despesa seja paga (art. 64, Lei n. 4.320/64). Apenas documentos processados pelos serviços de contabilidade podem exarar a ordem de pagamento (parágrafo único do art. 64).

190 SILVA, Orçamento-programa no Brasil, cit., p. 342.

191 MACHADO Jr.; REIS, cit., p. 149-150. 
A execução da despesa encerra-se com o pagamento. Esse só será efetuado quando ordenado após sua regular liquidação (art. 62, Lei n. 4.320/64). O art. 74 do Decreto-lei n. 200 estabelece que o pagamento se faça mediante ordem bancária ou cheque nominativo contabilizado pelo órgão competente, e obrigatoriamente assinado pelo ordenador da despesa e pelo encarregado do setor financeiro. Esse dispositivo legal derroga, assim, o art. 65 da Lei n. 4.320/64, que estabelecia a efetuação do pagamento por tesouraria ou pagadoria regularmente instituídas, por estabelecimentos bancários credenciados e, em casos excepcionais, por meio de adiantamento.

\subsection{CONCLUSÕES PARCIAIS}

O exame do regime de contabilidade pública no que toca o registro dos créditos e dotaçôes, como desdobramento técnico do princípio da legalidade serve para expor uma preocupação de índole político-constitucional: se há alguma incompatibilidade entre o cumprimento do orçamento votado pelo parlamento e a necessidade de sua adaptação às circunstâncias que se apresentem no momento da execução, ela é aparente. Os objetivos de eficiência da execução não podem ser compreendidos como uma etapa extra normativa ou alheia à legalidade do ciclo orçamentário. Executa-se o orçamento para cumprir o orçamento. Da mesma forma, muda-se o orçamento para que se torne possível cumprir seus objetivos.

De certa forma, a classificação das despesas apenas até um ponto em que não comprometa a eficiência administrativa, evitando previsões a tal ponto detalhadas que reduzam significativamente a discricionariedade administrativa, mostra que o orçamento público concede ao Poder Executivo margem para promover a adaptação do orçamento às necessidades mais específicas da administração. Contudo, ajustes maiores, que atinjam níveis mais amplos da classificação da despesa, afetando as próprias dotaçōes, devem retornar à apreciação parlamentar - o que é feito, na fase de execução, pela submissão de propostas de lei que criam créditos adicionais ou transferem recursos de uma dotação para outra.

Nota-se a preocupação da ordem jurídica com a manutenção de certo grau de flexibilidade também nas fases técnicas de execução da despesa, em que se procura ajustar o ritmo do empenho à existência de recursos suficientes. O contraste entre empenho e dotação orçamentária mostra, por si, que o sistema orçamentário reconhece a necessidade de cumprimento do orçamento aprovado, por meio da obediência ao que foi ali especificado. Essa é a lógica que deve presidir o regime de execução da despesa. A programação financeira e o cronograma do desembolso destinam-se a objetivos específicos: ajustar o ritmo da execução à conjuntura. De 
modo algum são um instrumento de planejamento descolados do sistema orçamentário, com prerrogativas autônomas à decisão parlamentar.

Se é possível identificar na flexibilidade da execução orçamentária o objetivo de permitir a realização dos programas orçamentários por meio de indispensáveis adaptações que surjam do ambiente econômico e social, é também possível supor que os instrumentos de flexibilização devam atender a tais objetivos. E caso surja necessidade de novo programa, não previsto, que se siga o processo legislativo. Há alguns meios de alteração dos créditos orçamentários, todavia, que fogem a essa orientação. 